\title{
Potential mechanisms underlying the acute lung dysfunction and bacterial extrapulmonary dissemination during Burkholderia cenocepacia respiratory infection
}

Luiz G Cunha Jr', Maria-Cristina Assis ${ }^{1}$, Gloria-Beatriz Machado ${ }^{1}$, Ana P Assef ${ }^{2}$, Elizabeth A Marques ${ }^{1}$, Robson S Leão', Alessandra M Saliba', Maria-Cristina Plotkowski ${ }^{1 *}$

\begin{abstract}
Background: Burkholderia cenocepacia, an opportunistic pathogen that causes lung infections in cystic fibrosis (CF) patients, is associated with rapid and usually fatal lung deterioration due to necrotizing pneumonia and sepsis, a condition known as cepacia syndrome. The key bacterial determinants associated with this poor clinical outcome in CF patients are not clear. In this study, the cytotoxicity and procoagulant activity of B. cenocepacia from the ET12 lineage, that has been linked to the cepacia syndrome, and four clinical isolates recovered from CF patients with mild clinical courses were analysed in both in vitro and in vivo assays.

Methods: B. cenocepacia-infected BEAS-2B epithelial respiratory cells were used to investigate the bacterial cytotoxicity assessed by the flow cytometric detection of cell staining with propidium iodide. Bacteria-induced procoagulant activity in cell cultures was assessed by a colorimetric assay and by the flow cytometric detection of tissue factor (TF)-bearing microparticles in cell culture supernatants. Bronchoalveolar lavage fluids (BALF) from intratracheally infected mice were assessed for bacterial proinflammatory and procoagulant activities as well as for bacterial cytotoxicity, by the detection of released lactate dehydrogenase.
\end{abstract}

Results: ET-12 was significantly more cytotoxic to cell cultures but clinical isolates $\mathrm{Cl}-2, \mathrm{Cl}-3$ and $\mathrm{Cl}-4$ exhibited also a cytotoxic profile. ET-12 and $\mathrm{Cl}-2$ were similarly able to generate a TF-dependent procoagulant environment in cell culture supernatant and to enhance the release of TF-bearing microparticles from infected cells. In the in vivo assay, all bacterial isolates disseminated from the mice lungs, but $\mathrm{Cl}-2$ and $\mathrm{Cl}-4$ exhibited the highest rates of recovery from mice livers. Interestingly, $\mathrm{Cl}-2$ and $\mathrm{Cl}-4$, together with $\mathrm{ET}-12$, exhibited the highest cytotoxicity. All bacteria were similarly capable of generating a procoagulant and inflammatory environment in animal lungs.

Conclusion: B. cenocepacia were shown to exhibit cytotoxic and procoagulant activities potentially implicated in bacterial dissemination into the circulation and acute pulmonary decline detected in susceptible CF patients. Improved understanding of the mechanisms accounting for B. cenocepacia-induced clinical decline has the potential to indicate novel therapeutic strategies to be included in the care B. cenocepacia-infected patients.

\footnotetext{
* Correspondence: crisplot@yahoo.com.br

'Departamento de Microbiologia, Imunologia e Parasitologia, Faculdade de

Ciências Médicas, Universidade do Estado do Rio de Janeiro, Brazil
} 


\section{Background}

Over the last decades, Burkholderia cenocepacia has emerged as an important respiratory pathogen in the cystic fibrosis (CF) community. Pulmonary colonization/ infection by these bacteria may persist for months or even years but a minority of patients exhibits a rapid clinical deterioration associated with severe respiratory inflammation, epithelial necrosis and invasive disease, a condition known as cepacia syndrome [1]. Despite intense research efforts, the detailed pathogenic mechanisms underlying this poor outcome of $\mathrm{CF}$ patients are not clear. B. cenocepacia ability to induce a marked release of proinflammatory mediators [2-4] is likely to contribute to lung damage and respiratory failure but whether bacterial isolates recovered from patients with poor clinical prognosis exhibit differential virulence profile has been so far poorly investigated.

Increasing evidences suggest that inflammation and coagulation are linked to and amplify each other. In clinical settings associated with exacerbated inflammatory response, uncontrolled activation of the coagulation cascade leads ultimately to inadequate fibrin deposition in host microvasculature [5]. In lungs, fibrin deposition has also been demonstrated in the alveolar and interstitial compartments [6,7]. Alveolar clotting processes compromise the lung gas-exchange barrier. Moreover, thrombin and fibrin degradation products may further activate neutrophils and fibroblasts, contributing to lung injury. Because the lungs of CF patients is characterized by a florid inflammatory response, we wonder whether alveolar clotting processes may be involved in the pathogenesis of pulmonary decline observed in a proportion of B. cenocepacia-infected CF patients.

Coagulopathy associated with inflammatory response depends most notably on enhanced expression of tissue factor (TF), the major physiological initiator of the coagulation cascade [8]. Besides being expressed on different cell types, TF can be released from cell surfaces and circulate in extracellular fluids as a soluble fluid-phase protein [9] or associated with microparticles [10] shed from cell membranes upon cell activation and/or damage. Because microparticles exhibit also anionic phosphatidylserine at their surface, they provide a catalytic surface promoting the assembly of the enzyme complexes of the coagulation cascade, contributing to the thrombogenicity of extracelular fluids $[10,11]$.

Different pathogens have been shown to up-regulate TF expression on human cells [12-14], thereby enhancing their procoagulant potential but, to our knowledge, the ability of $B$. cenocepacia to modulate TF expression has not yet been investigated.

To address the deficiency in the knowledge of B. cenocepacia pathogenicity, in the present study we compared bacteria of the ET-12 epidemic lineage, that has been linked to the cepacia syndrome [15], with four B. cenocepacia clinical isolates $(\mathrm{CI})$ recovered from the airways of CF patients with mild clinical outcome in their expression of virulence features potentially implicated in invasive disease and lung function decline: cytotoxicity towards airway epithelial respiratory cells and ability to induce a procoagulant state in the lung environment.

\section{Materials and methods}

\section{Bacterial strains and culture conditions}

B. cenocepacia strain J2315, a member of the virulent lineage known as electrophoretic type 12 (ET-12), was provided by the Pasteur Institute microorganisms depository. Clinical isolates ( $\mathrm{Cl}-1$ to $\mathrm{Cl}-4)$ were recovered from the airway secretions of four different $\mathrm{CF}$ patients and belong to B. cenocepacia subgroup IIIA. Samples obtained from the patients were processed as described previously [16]. Bacteria were grown on Trypticase Soy Broth at $37^{\circ} \mathrm{C}$ for about $18 \mathrm{~h}$, harvested by centrifugation and resuspended in M-199-HEPES medium (Gibco BRL, Gaithersburg, MD, USA) containing $10 \%$ fetal calf serum (FCS) to $A_{660} \mathrm{~nm}=0.1$, corresponding to about $10^{8}$ colony forming units (CFU)/mL.

\section{Airway epithelial cell culture}

Transformed human bronchial epithelial cells from the BEAS-2B cell line were cultured in M-199-HEPES medium containing 10\% FCS and glutamine (complete medium), and seeded in 24-well tissue culture plates $\left(0.4 \times 10^{5}\right.$ cells per well). After $48 \mathrm{~h}$, cells were infected at a multiplicity of infection of about 100 bacteria per cell. Bacteria were centrifuged $(1,000 \mathrm{~g}$ for $10 \mathrm{~min})$ onto the cell monolayers prior to incubation at $37^{\circ} \mathrm{C}$ for $1 \mathrm{~h}$. Cells were then incubated with complete culture medium containing gentamicin $(1 \mathrm{mg} / \mathrm{mL})$ and ceftazidime $(1 \mathrm{mg} / \mathrm{mL})$ for additional $19 \mathrm{~h}$, to eliminate infecting microorganisms, as reported [2]. Control non-infected cells were treated similarly.

\section{Detection of bacterial cytotoxicity}

Bacterial cytotoxicity was determined by the assessment of cell staining with propidium iodide, a cell-impermeable nucleic acid binding dye that only permeates leaky cell membranes [17]. Briefly, control and infected cells were detached from the microplate wells with $0.05 \%$ trypsin- $0.02 \%$ EDTA solution, pooled with spontaneously detached cells present in culture supernatants, centrifuged, ressuspended in PBS containing 1\% bovine serum albumin (PBS-BSA 1\%), incubated with propidium iodide at a final concentration of $2 \mu \mathrm{g} / \mathrm{mL}$ for 10 min and analyzes with a FACscalibur flow cytometer (Becton Dickinson, Mountain View, CA, USA).

\section{Detection of cell-associated TF}

Control and infected cells were detached from the microplate wells as described above, fixed with $4 \%$ 
paraformaldehyde and saccharose in PBS, permeabilized with $0.01 \%$ Triton X-100 in PBS for 5 min, rinsed, incubated with an anti-TF-FITC complex (American Diagnostica, Stanford, CT, USA) and analyzed by flow cytometry.

\section{Detection of TF and procoagunlant activity in cell culture} supernatant

The Imubind TF ELISA and Actichrome TF activity kits (American Diagnostica) were used to quantify TF and detect a procoagulant activity, respectively, in cell culture supernatants, according to the manufacturer's instructions.

\section{Detection of TF-containing microparticles}

Cell culture supernatants from control and infected cultures were centrifuged at $1,200 \mathrm{~g}$ for $3 \mathrm{~min}$, to remove cell debris, and then centrifuged at 17,500 g for $30 \mathrm{~min}$ at $15^{\circ} \mathrm{C}$, to pellet microparticles. Pellets were washed, treated simultaneously with the anti-TF-FITC and annexin V-Alexa Fluor 647 (Molecular Probes, Eugene, OR, USA) complexes for $30 \mathrm{~min}$ in ice and washed once with PBS. Microparticles were resuspended in PBS-BSA $1 \%$ and analyzed for 1 min by flow cytometry. The region corresponding to shed microparticles was gated in side scatter versus fluorescent intensity dot plot representations by using, as reference, a mix of fluorescent beads (Megamix; Biocytex, Marseille, France) of diameters to cover the microparticles $(0.5 \mu \mathrm{m}$ and 0.9 $\mu \mathrm{m})$, as described [14].

\section{Analysis of chromosomal B. cenocepacia DNA restriction} profiles

Isolates were typed by pulse field gel electrophoresis (PFGE) as described [18], following digestion of intact genomic DNA with SpeI (Invitrogen). DNA fragments were separated on $1 \%(\mathrm{w} / \mathrm{v})$ agarose gels in $0.5 \% \mathrm{TBE}$ (Tris-borate-EDTA) buffer using a CHEF DRIII apparatus (Bio-Rad, Hercules, CA, USA) with $6 \mathrm{~V} / \mathrm{cm}$, pulsed from 0.5 to $25 \mathrm{~s}$, for $18 \mathrm{~h}$ and 30 to $60 \mathrm{~s}$, for $3 \mathrm{~h}$ at $14^{\circ}$ C. Gels were stained with ethidium bromide and photographed under ultraviolet light.

\section{In vivo assays}

Female 8-12 wk old Swiss mice were injected intraperitoneally with cyclophosphamide $(150 \mathrm{mg} / \mathrm{kg})$ to induce granulocytopenia and favour acute B. cenocepacia infection. After $48 \mathrm{~h}$, mice were anesthetized with a mixture of ketamine $(65 \mathrm{mg} / \mathrm{kg})$ and xylazine $(13 \mathrm{mg} / \mathrm{kg})$ administered intraperitoneally and $5 \times 10^{7} \mathrm{CFU}$ of each bacterial isolate in $50 \mu \mathrm{L}$ of sterile LPS-free saline were instilled into their tracheas. Control mice were instilled with sterile LPS-free saline. After $24 \mathrm{~h}$, mice were anesthetized for blood collection by intracardiac puncture (for bacteriological culture and the assessment of leukocyte concentration), and killed by intraperitoneal injection of sodium pentobarbital. Mice airways were then washed with $1 \mathrm{~mL}$ of PBS, their livers were excised, macerated and serially diluted with sterile saline. Bacterial load in liver parenchyma was determined by plating serial dilution of liver macerates on blood agar plates. Mice bronchoalveolar lavage fluids (BALFs) were analysed for total leukocyte and protein concentration (BCA Protein Assay kit, Pierce Biotechnology, Rockford, IL, USA), as well as for lactate-dehydrogenase (LDH) (Sigma-Aldrich, St Louis, MO, USA) and procoagulant activity (American Diagnostica). Animal handling were in accord with the guidelines of the Animal Ethics Research Committee of the State University of Rio de Janeiro (protocol \# CEA/210/2007).

\section{Statistical analysis}

Statistical analysis was performed using a one-way analysis of variance (ANOVA) with the Bonferroni's test to determine significant differences between groups, unless otherwise stated. $\mathrm{P}$ values $<0.05$ were deemed to be significant.

\section{Results}

\section{B. cenocepacia isolates differed in their cytotoxicity}

With the exception of $\mathrm{Cl}-1$, all bacteria killed significantly high percentages of airway cells (Fig. 1). B. cenocepacia from the ET-12 lineage was shown to be significantly more cytotoxic than the other isolates $(\mathrm{p}<$ $0.001,0.01,0.001$ and 0.05 when compared with $\mathrm{Cl}-1$, $\mathrm{Cl}-2, \mathrm{Cl}-3$ and $\mathrm{Cl}-4$, respectively).

\section{B. cenocepacia did not modify the expression of TF by infected cells but enhanced the release of TF into cell supernatants}

No significant difference between control and infected cultures in their percentage of TF-expressing cells could be detected (Fig. 2A), as well as their expression of TF mRNA (data not shown). In contrast, TF concentrations in supernatants from ET-12- and Cl-2-infected cultures were significantly higher than in supernatant from noninfected cultures and from cultures infected with the other clinical isolates, $\mathrm{Cl}-2$ infection being the most important stimulus for TF release (Fig. 2B).

The biological relevance of released TF was next investigated. Fig. $2 \mathrm{C}$ shows that the supernatants from ET-12 and Cl-2-infected cells exhibited a significantly augmented procoagulant activity when compared with supernatants from control cultures and from cultures infected with the other clinical isolates ( $\mathrm{p}<0.01$ for $\mathrm{Cl}-$ 1 and $\mathrm{p}<0.05$ for $\mathrm{Cl}-3$ and $\mathrm{Cl}-4$ ).

\section{B. cenocepacia enhanced also the release of TF-bearing} microparticles

Fig. 3A shows that the number of microparticles binding annexin $\mathrm{V}$, a protein known for its interaction with negatively charged phosphatidylserine residues, was significantly higher in supernatants from ET-12- and Cl-2infected cells than in supernatants from control cultures. More importantly, a higher percentage of MPs shed 


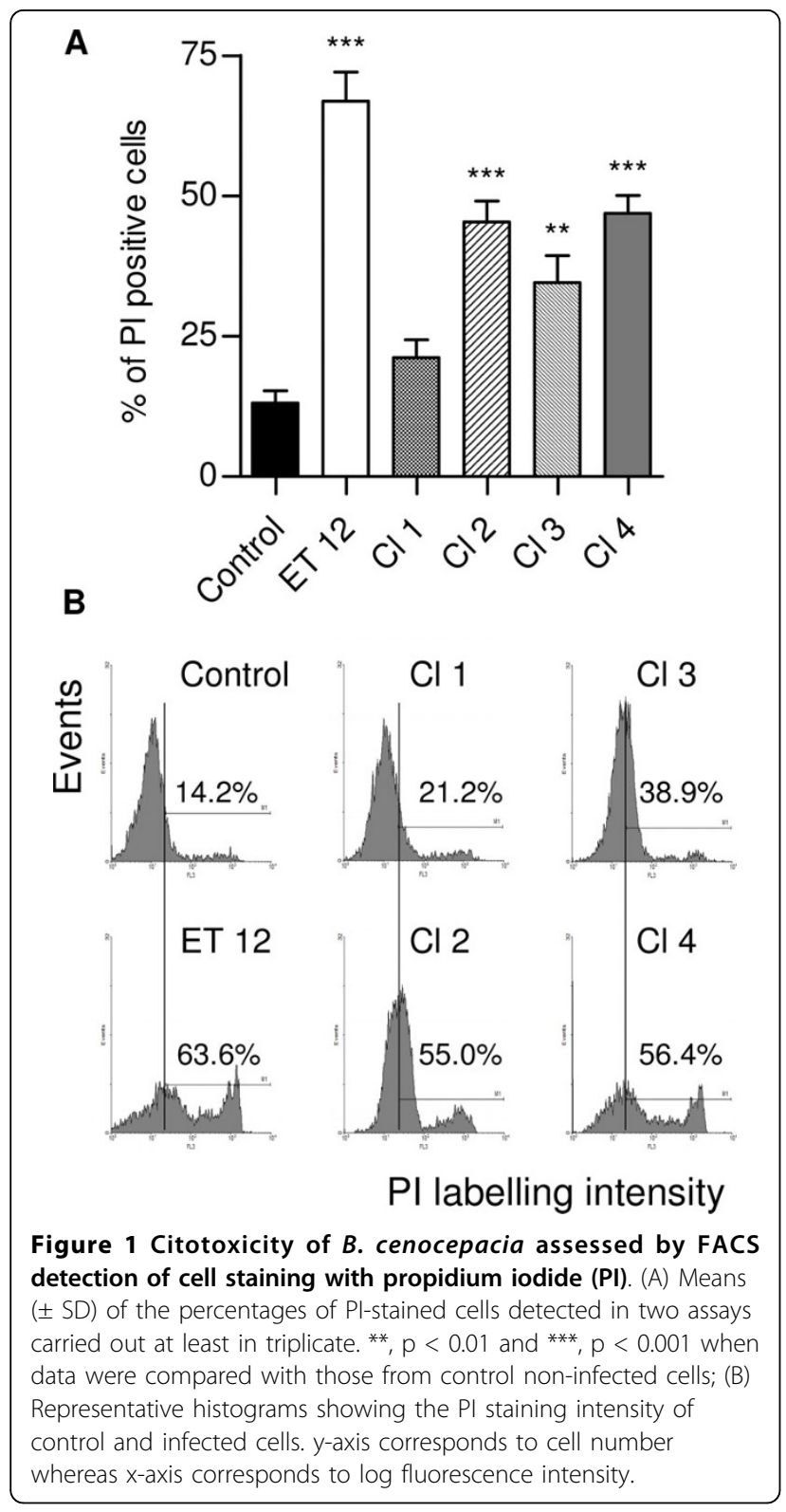

after ET-12 and Cl-2 infection, besides reacting with annexin V, exhibited surface TF (Fig. 3B).

\section{Genetic relatedness of the $B$. cenocepacia isolates}

Because ET-2 and Cl-2 exhibited a similar virulence profile, we wondered whether these two isolates were clonally related. However, PFGE analysis showed that all bacteria belonged to a different clonal group, with $70 \%$ maximum similarity, with the exception of $\mathrm{Cl}-1$ and $\mathrm{Cl}-$ 2 that exhibited exactly the same chromosomal DNA profile (Fig. 4).

\section{In vivo assays}

Total leukocyte concentrations in peripheral blood from mice infected with all clinical isolates were significantly lower than in blood from control mice, testifying the
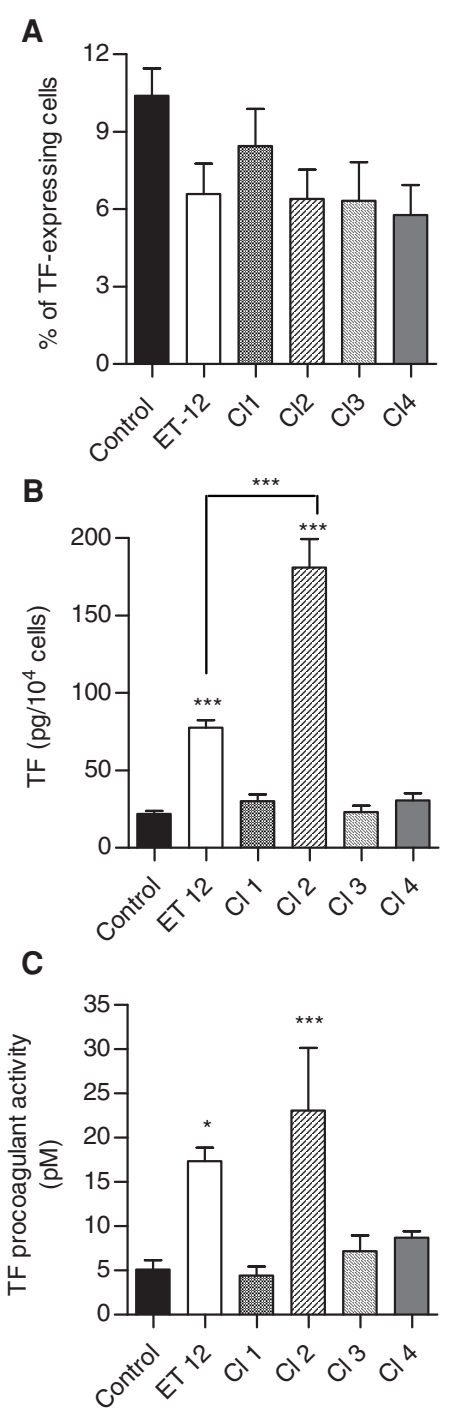

Figure 2 Modulation of TF expression in infected cultures. (A) Percentage of TF-expressing cells in control and infected cultures, determined by FACS analysis; (B) Concentration of TF in supernatants from control and infected airway epithelial cell cultures. (C) Procoagulant activity in cell culture supernatants. Data are means $( \pm S D)$ of the results obtained in at least two different assays carried out in tripicate. ${ }^{*}, p<0.05$ and ${ }^{*}, p<0.01$ and $p<$ 0.001 when data were compared with the results obtained with control non-infected cultures.

disease severity (Fig. 5A). All isolates were able to disseminate from the primary site of infection, as revealed by positive hemocultures for $B$. cenocepacia in all infected mice (data not shown). However, the percentages of $\mathrm{Cl}$ 2- and Cl-4-infected mice with positive liver cultures were higher than the percentages of mice infected with the other bacterial isolate, including ET-12, although the differences were not statistically significant (Fig. 5B). Bacterial concentration were also higher in liver parenchyma from $\mathrm{Cl} 2$ - and $\mathrm{Cl}$ 4-infected mice (Fig. 5C). 

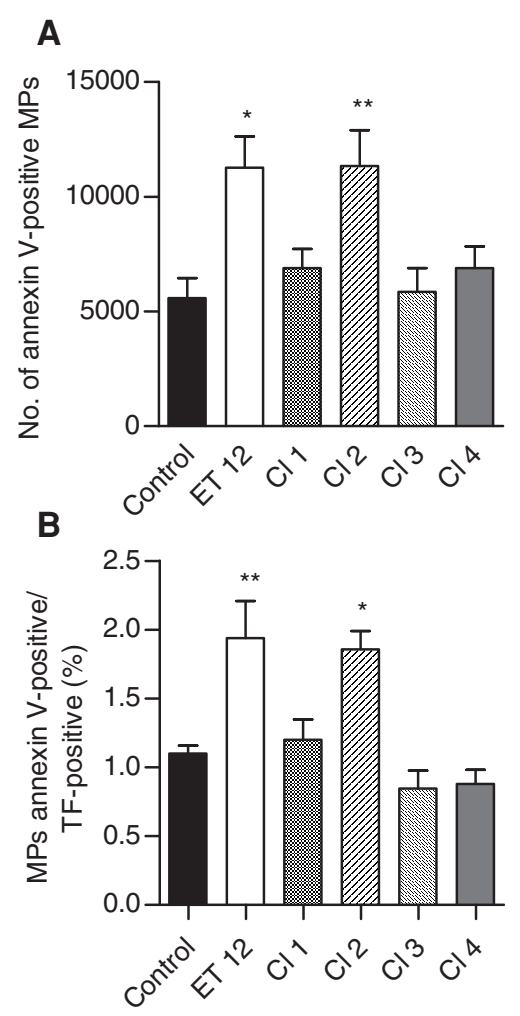

Figure 3 Microparticle release from control and infected cells (A) Number of microparticles in control and infected cell culture supernatants submitted to FACS analysis for 1 min; (B) Percentage of TF positive/annexinV positive microparticles in supernatant from control and infected cultures. Data are means ( \pm SD) of the results obtained in two assays carried out in triplicate. ${ }^{*}, p<0.05$ and ${ }^{*}, \mathrm{p}$ $<0.01$ when data from control and infected cells were compared with each other.

Infection with all B. cenocepacia isolates resulted in an inflammatory environment in mice lungs, revealed by significantly increased BALF concentrations of total protein and leukocyte (Fig. 6A and 6B, respectively). Most cells in BALFs from control mice were mononuclear $(83.0 \% \pm 15.9)$, whereas in fluids from infected animals most cells were polymorphonuclear (from $84.0 \% \pm 10.6$ to $96.1 \% \pm 3.2)$. $\mathrm{LDH}$ concentrations in samples from infected mice were higher than in samples from control mice, testifying the bacterial cytotoxicity, although statistically significant differences were only detected when BALFs from control mice were compared with BALFs from ET-12-, Cl-2- and Cl-4-infected mice (Fig. 6C). BALFs from all infected mice exhibited a significant TFdependent procoagulant activity (Fig. 6D).

\section{Discussion}

Bacteria causing respiratory infections in CF patients typically remain confined to the endobronchial spaces. In contrast, a proportion of $B$. cenocepacia-infected patients exhibits an invasive disease, characterized by bacterial extrapulmonary dissemination and systemic inflammatory response [15]. The mechanisms that permit bacteria to disseminate are not yet known but are likely to involve penetration of airway barriers. In vitro studies provided evidences that $B$. cenocepacia from the ET-12 lineage can increase the permeability of and traverses polarized respiratory epithelium [19] by the dephosphorylation and dissociation of occludin from the tight-junction complex [20]. However, increase in epithelium permeability can also be secondary to epithelial cell death resulting in breachs of the epithelium barrier properties. Interestingly, evidences of damage to airway epithelial cells in culture were detected in areas subjacent to B. cenocepacia biofilms [19]. Cell damage was also detected in airway epithelial cell cultures infected with bacterial isolates carrying the cable pilin gene (21), a distinctive feature of $B$. cenocepacia from the ET-12 lineage [1]. More recently, purified cable pili were found to directly induce cytotoxicity in airway epithelial cells in vitro [22].

In the in vitro assays of this present study, besides ET12 , most clinical $B$. cenocepacia isolates were shown to kill airway epithelial cells but the specific virulence determinant and the corresponding genetic element required for $B$. cenocepacia cytotoxicity were not investigated. Interestingly, in the in vivo assay, clinical isolates accounting for the highest $\mathrm{LDH}$ concentration in mice BALF ( $\mathrm{Cl}-2$ and $\mathrm{Cl}-4$ ) were recovered in higher frequency and concentrations in liver parenchyma. On the basis of these results, it is tempting to suggest a

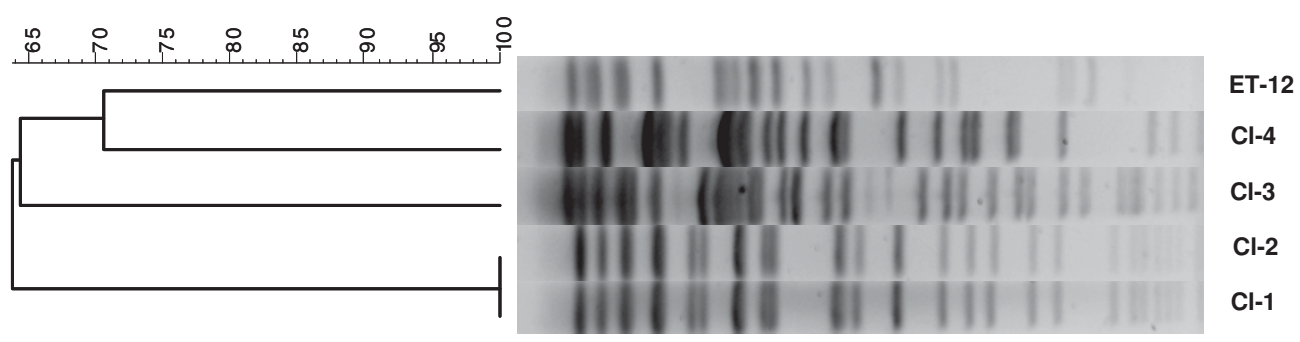

Figure 4 PFGE profiles of genomic B. cenocepacia DNAs and dendogram resulting from computer analysis of PFGE profiles. 

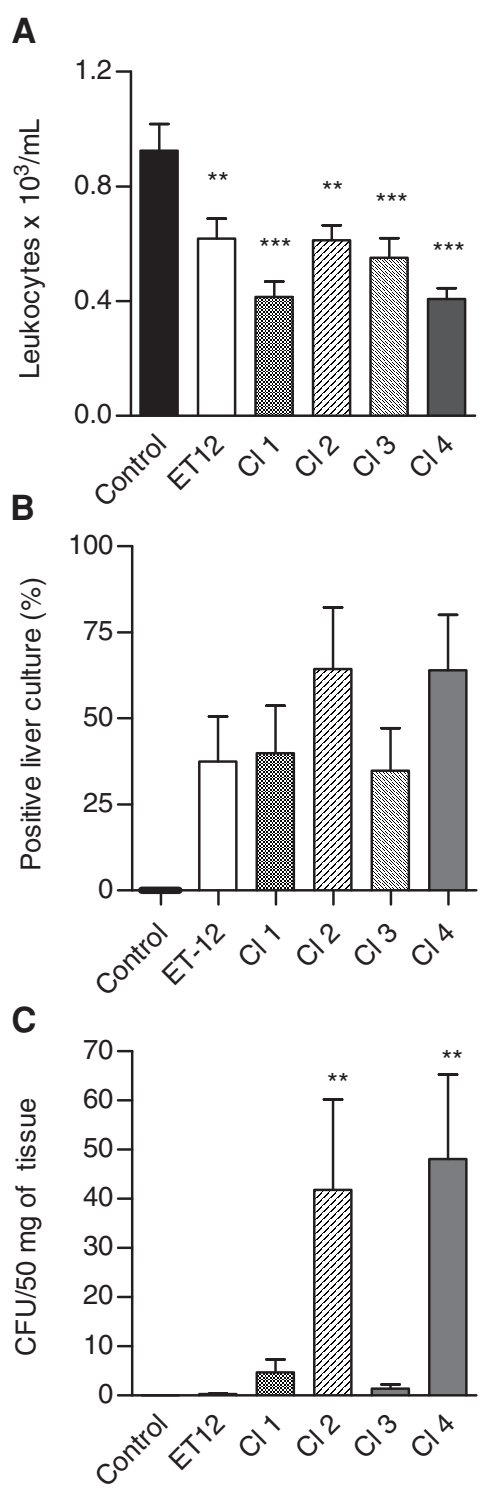

Figure 5 (A) Blood leukocyte concentration in control and infected mice. Data are means $( \pm S D)$ of the results obtained in two assays in which at least 12 animals from each group were analysed. ${ }^{* *}, p<0.01$ and ${ }^{* * *}, p<0.001$ when data from control and infected mice were compared with each other. (B) Percentage of mice from each group with positive liver cultures; (C) Bacterial concentration in liver parenchyma. ${ }^{*}, \mathrm{p}<0.01$ when data from $\mathrm{Cl}$ 2- and $\mathrm{Cl}$-4-infected mice were compared with data from the other groups by the Wilcoxon nonparametric test.

relationship between bacterial cytotoxicity and dissemination into the circulation. However, since such relationship was not detected in ET-12-infected mice, further studies are required to examine this hypothesis.

A huge inflammatory reaction is a hallmark of CF patient lung parenchyma [15]. Because inflammation almost invariably leads to the activation of the coagulation cascade [5], and intra-alveolar fibrin deposition plays a pathogenic role in lung dysfunction detected in many acute inflammatory lung diseases [23], we wondered whether $B$. cenocepacia would induce a procoagulant state in patient airspaces.

Increase of lung procoagulant state depends on enhanced expression of TF by airway cells followed by local TF-induced activation of the coagulation, in addition to being influenced by insufficiency of natural inhibitors of coagulation and of the fibrinolytic system [24]. Prominent among the proinflammatory stimuli known to modulate TF expression in monocyte and endothelial cells is bacterial LPS [25]. LPS was also shown to upregulate TF expression in lung tissues and fibrin deposition in the alveolar spaces, bronchioles and vessels of experimental animals [26]. Because B. cenocepacia LPS is a potent inducer of the inflammatory response $[27,28]$, we were surprised to find no increase in TF expression in infected airway epithelial cells. A similar result was recently described in airway cell cultures infected with an ExoU-deficient $P$. aeruginosa strain [14]. Since most in vitro studies showing the regulatory effect of LPS on TF expression have been carried out with monocyte/macrophages or endothelial cells, we wonder whether the apparent contradiction between our results and the others may have stemmed from differential response of these several cell types. Alternatively, it is conceivable that the concentration of LPS released from infecting bacteria during the experimental assays may be much lower than the concentration of purified LPS used in those in vitro studies.

In contrast with the absence of modulation of TF expression at airway cells surface, significantly increased TF concentration and procoagulant activity were detected in supernatants from ET-12- and Cl-2-infected cells. These two bacterial isolates elicited also a significant release of TF-bearing microparticles from airway cells. Although the procoagulant activity detected in culture supernatants may have resulted from released soluble fluid-phase TF, it most likely resulted from the release of TF-bearing microparticle. This is so because TF requires association with anionic lipids to become procoagulant [29]. Whereas anionic lipids are not associated with soluble fluid-phase TF, they are constitutively expressed in microparticles. Studies showing that circulating TF-bearing microparticles are often associated with thrombotic propensity $[10,11]$ corroborate our hypothesis.

Differences between the results from $B$. cenocepaciainduced procoagulant activity in cell culture supernatants and in mice BALFs are likely reflect the complexity of the in vivo experimental model in which different cell types are likely to contribute to the generation of the procoagulant activity. Because TF expression in cells from the monocytic lineage IS enhanced substantially 

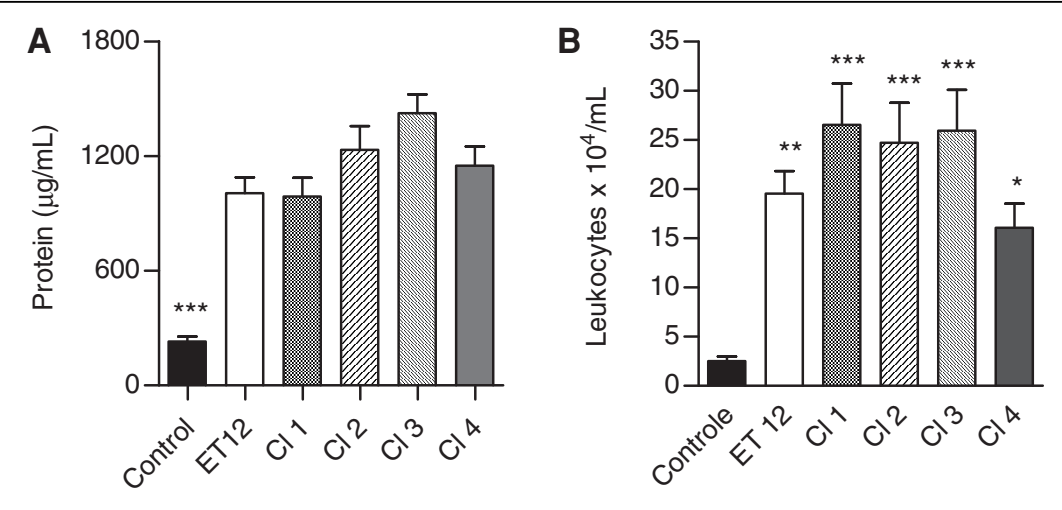

C

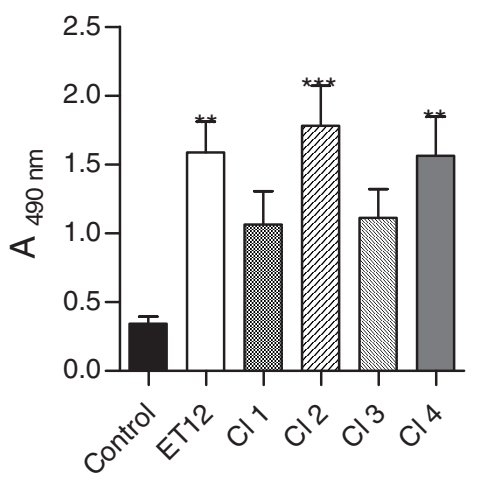

D

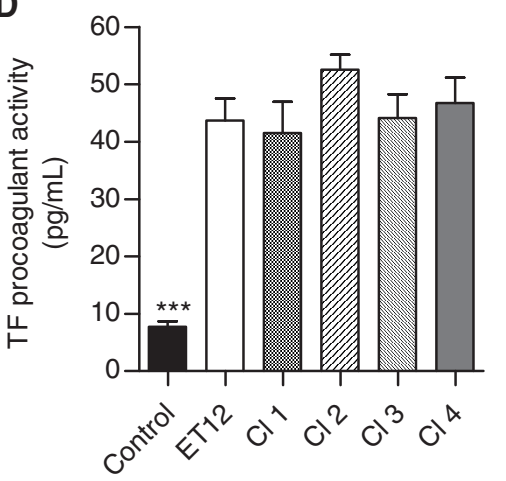

Figure 6 (A) Total protein, (B) leukocyte, (C) LDH concentrations and (D) procoagulant activity in BALFs from control and infected mice. Data are means ( \pm SD) of the results obtained two assays in which at least 12 animals from each group were analysed ${ }^{*}, p<0.05,{ }^{* *}, p<$ $0.01,{ }^{* *}, p<0.001$ when data from control and infected mice were compared with each other.

upon cell activation, we wonder whether B. cenocepaciastimulated alveolar macrophage may have contributed the generation of a potent TF-dependent procoagulant activity in mice BALFs, surmounting a milder response of airway epithelial cells.

In this report, in both in vitro and in vivo assays, Cl-2 was phenotypically similar to ET-12 B. cenocepacia but these two bacteria exhibited a very different PFGE profile. On the other hand, B. cenocepacia $\mathrm{Cl}-1$ and $\mathrm{Cl}-2$, that were indistinguishable by PFGE analysis, differed markedly in their virulence properties against airway cells.

$B$. cenocepacia possess very large genomes and separate their DNA into three or more chromosomal replicons which may add greater flexibility in the acquisition, loss and expression of genes [30,31]. Indeed, genomesequencing projects have shown that $10 \%$ of more of the Burkholderia genes have been acquired through gene horizontal transfer and reside as elements of foreign DNA such as genomic islands, prophages or plasmids. Therefore, it is conceivable that genes encoding virulence factors accounting for the cytotoxicity and procoagulant activity of $B$. cenocepacia ET-12 and Cl-2 may reside as elements of foreign DNA that are not possessed by all B. cenocepacia isolates and were not detected by PFGE analysis. Similarly, foreign DNA elements possessed by $\mathrm{Cl}-2$, but not by $\mathrm{Cl}-1$, would explain why these two bacterial isolates, that exhibit the same chromosomal DNA profile, have different virulence phenotypes. Studies to examine this hypothesis are currently in progress.

\section{Conclusion}

In this report, B. cenocepacia from the ET-12 lineage and clinical isolates were shown to exhibit virulence features potentially implicated in bacterial dissemination into the circulation and acute pulmonary decline detected in susceptible CF patients: cytotoxicity to airway epithelial cells, capability of enhancing the release of TF-bearing microparticles from infected cells and generating a TF-dependent procoagulant environment. In vivo assays corroborated the $B$. cenocepacia cytotoxicity as well as the ability to generate a procoagulant and inflammatory environment in mice airways.

Although differences between experimental models and humans preclude direct extrapolation of results from experimental studies to patients, on the basis of our in vitro and in vivo evidences we speculate that at least some $B$. cenocepacia isolates may be able to induce a prothrombotic state in CF patient airways, ultimately resulting in deposition of fibrin in airspaces. This 
hypothesis is supported by our recent demonstration of thrombus formation in lung parenchyma of Pseudomonas aeruginosa-infected mice with increased local procoagulant activity $[14,32]$. Besides compromising the lung gas-exchange barrier, airway clotting processes are harmful because surfactant components may be incorporated into polymerizing fibrin with subsequent loss of surface activity and alveolar instability, further contributing to lung function deterioration. Improved understanding of the mechanisms accounting for $B$. cenocepacia-induced procoagulant activity has the potential to indicate novel therapeutic strategies to be included in the care B. cenocepacia-infected patients.

\section{Acknowledgements}

We thank Maria Angelica P. da Silva, Marcia Jones and Wagner Brito (Department of Microbiology, Immunology and Parasitology, State University of Rio de Janeiro, Brazil) for their technical assistance. This work was supported by grants from CNPq (470131/2006-3) and FAPERJ (E-26/100.587/ 2007 and E-26/1000.417/2007) Brazilian funding agencies.

\section{Author details}

${ }^{1}$ Departamento de Microbiologia, Imunologia e Parasitologia, Faculdade de Ciências Médicas, Universidade do Estado do Rio de Janeiro, Brazil. ${ }^{2}$ Laboratório de Pesquisa em Infecção Hospitalar, IOC/FIOCRUZ, Rio de Janeiro, Brazil.

\section{Authors' contributions}

LGCJ performed most of the assays. MCA contributed to the design of the study and participated of all flow cytometry assays. GBM participated of all in vivo assays. APDCA, RSL and AMS participated of the molecular biology studies. EAM contributed to the design of the study. MCP conceived and coordinated the study, participated in statistical analysis and wrote the manuscript. All authors read and approved the final manuscript.

\section{Competing interests}

The authors declare that they have no competing interests.

Received: 21 September 2009

Accepted: 18 January 2010 Published: 18 January 2010

\section{References}

1. Mahenthiralingam E, Baldwin A, Dowson CG: Burkholderia cenocepacia complex bacteria: opportunistic pathogens with important natural biology. J Appl Microbiol 2008, 104:1539-1551.

2. Moura JA, Assis MC, Ventura GMC, Saliba AM, Gonzaga L Jr, Si-Tahar M, Marques EA, Plotkowski MC: Differential interaction of bacterial species from the Burkholderia cepacia complex with human airway epithelial cells. Microbes Infect 2008, 10:52-59.

3. Sajjan US, Hershenson MB, Forstner JF, LiPuma JJ: Burkholderia cenocepacia ET12 strain activates TNFR1 signalling in cystic fibrosis airway epithelial cells. Cell Microbiol 2008, 10:188-201.

4. Ventura GMC, Balloy V, Ramphal R, Khun H, Huerre M, Ryffel B, Plotkowski MC, Chignard M, Si-Tahar M: Lack of MyD88 protects the immunodeficient host against fatal lung inflammation triggered by the opportunistic bacteria Burkholderia cenocepacia. J Immunol 2009, 183:670-767.

5. Levi M, Keller TT, van Gorp E, Cate H: Infection and inflammation and the coagulation system. Cardiovasc Res 2003, 60:26-39.

6. Martin GS, Bernard GR: Airway and lung in sepsis. Intensive Care Med 2001, 27(suppl 1):S63-S79.

7. Seeger W, Hübel J, Klapettek K, Pison U, Obertacke U, Joka T, Roka L: Procoagulant activity in bronchoalveolar lavage of severely traumatized patients-relation to the development of acute respiratory distress. Thromb Res 1991, 61:53-64.
8. Chu AJ: Tissue factor mediates inflammation. Arch Biochem Biophys 2005, 15:123-132.

9. Giesen $\mathrm{PL}$, Rauch U, Bohrmann B, Kling D, Roqué M, Fallon JT, Badimon J J, Himber J, Riederer MA, Nemerson Y: Blood-borne tissue factor: another view of thrombosis. Proc Nat Acad Sci USA 1999, 96:2311-2315.

10. Morel O, Toti F, Hugel B, Freyssinet JM: Cellular microparticles: a disseminated storage pool of bioactive vascular effectors. Curr Opin Hematol 2004, 11:156-164.

11. Hugel B, Matinez MC, Kunzelamann C, Freyssinet JM: Membrane microparticles: two sides of the coin. Physiol 2005, 20:22-27.

12. Bryant $A E$, Hayes-Schroer SM, Stevens DL: $M$ type 1 and 3 group $A$ streptococci stimulate tissue factor-mediated procoagulant activity in human monocytes and endothelial cells. Infect Immun 2003, 71:1903-1910.

13. Mattsson E, Heying R, Gevel van de JS, Hartung T, Beekhuizen H: Staphylococcal peptidoglycan initiates an inflammatory response and procoagulant activity in human vascular endothelial cells: a comparison with highly purified lipoteichoic acid and TSST-1. FEMS Immunol Med Microbiol 2008, 52:110-117.

14. Plotkowski MC, Feliciano LF, Machado GB, Cunha LG Jr, Freitas C, Saliba AM, de Assis MC: ExoU-induced procoagulant activity in Pseudomonas aeruginosa-infected airway cells. Eur Respir J 2008, 32:1591-1598.

15. Mahenthiralingam E, Baldwin A, Vandame P: Burkholderia cepacia complex infection in patients with cystic fibrosis. J Med Microbiol 2002, 51:533-538.

16. Carvalho GMV, Carvalho APA, Folescu TW, Higa L, Teixeira LM, Plotkowski MC, Merquior VL, Albano RM, Marques EA: Transient isolation of Burkholderia multivorans and Burkholderia cenocepacia from a Brazilian cystic fibrosis patient chronically colonized with Burkholderia vietnamiensis. J Cystic Fibrosis 2005, 4:267-270.

17. Jone $K H$, Senft JA: An improved method to determine cell viability by simultaneous staining with fluorescein diacetate and propidium iodide. $J$ Histochem Cytochem 1985, 33:77-79.

18. Carvalho APA, Ventura GMC, Pereira CB, Leão RS, Folescu TW, Higa L, Teixeira LM, Plotkowski MC, Merquior VLC, Albano RM, Marques EA: Burkholderia cenocepacia, B. multivorans, B. ambifaria and $B$. vietnamiensis isolates from cystic fibrosis patients have different profiles of exoenzyme production. APMIS 2007, 115:311-318.

19. Schwab U, Leigh M, Ribeiro C, Yankaskas J, Burns K, Gilligan P, Sokol P, Boucher R: Patterns of epithelial cell invasion by different species of the Burkholderia cepacia complex in well-differentiated human airway epithelia. Infect Immun 2002, 70:4547-4555.

20. Kim JY, Sajjan US, Krasan GP, LiPuma JJ: Disruption of Tight Junctions during Traversal of the Respiratory Epithelium by Burkholderia cenocepacia. Infect Immun 2005, 73:7107-7112.

21. Sajjan U, Ackerley C, Forstner J: Interaction of cblA /adhesin-positive Burkholderia cepacia with squamous epithelium. Cell Microbiol 2002, 4:73-86.

22. Cheung KJ Jr, Li G, Urban TA, Goldberg JB, Griffith A, Lu F, Burns JL: Pilusmediated epithelial cell death in response to infection with Burkholderia cenocepacia. Microbes Infect 2007, 9:829-837.

23. Bastarache JA, Wang L, Geiser T, Wang Z, Albertine KH, Matthay MA, Ware LB: The alveolar epithelium can initiate the extrinsic coagulation cascade through expression of tissue factor. Thorax 2007, 62:608-616.

24. Levi M, Schultz MJ, Rijneveld AW, Poll van der T: Bronchoalveolar coagulation and fibrinolysis in endotoxemia and pneumonia. Crit Care Med 2003, 31:S238-S242.

25. Cohen J: The immunopathogenesis of sepsis. Nature 2002, 420:885-891.

26. Wygrecka M, Markart P, Ruppert C, Kuchenbuch T, Fink L, Bohle RM, Grimminger F, Seeger W, Günther A: Compartment- and cell-specific expression of coagulation and fibrinolysis factors in the murine lung undergoing inhalational versus intravenous endotoxin application. Thromb Haemost 2004, 92:529-540.

27. Zughaier SM, Ryley HC, Jackson SK: LPS from Burkholderia cepacia is more active than LPS from Pseudomonas aeruginosa and Stenotrophomonas maltophilia in stimulating TNF- $\alpha$ from human monocytes. Infect Immun 1999, 67:1505-1507.

28. De Soyza A, Ellis CD, Khan CM, Corris PA, Demarco de Hormaeche R: Burkholderia cenocepacia lipopolysaccharide, lipid A, and proinflammatory activity. Am J Respir Crit Care Med 2004, 170:70-77. 
29. Sturk-Maquelin KN, Nieuwland R, Romijn FP, Eijsman L, Hack CE, Sturk A: Pro- and non-coagulant forms of non-cell-bound tissue factor in vivo. J Thromb Haemost 2003, 1:1920-1926.

30. Mahenthiralingam E, Urban TA, Goldberg JB: The multifarious, multireplicon BC complex. Nat Rev Microbiol 2005, 3:144-156.

31. Holden MTG, Seth-Smith HMB, Crossman LC, Sebaihia M, Bentley SD, Cerdeño-Tárraga AM, Thomson NR, Bason N, Quail MA, Sharp S,

Cherevach I, Churcher C, Goodhead I, Hauser H, Holroyd N, Mungall K, Scott P, Walker D, White B, Rose H, Iversen P, Mil-Homens D, Rocha EPC, Fialho AM, Baldwin A, Dowson C, Barrell BG, Govan JR, Vandamme P, Hart CA, Mahenthiralingam E, Parkhill J: The genome of Burkholderia cenocepacia J2315, an epidemic pathogen of cystic fibrosis patients. J Bacteriol 2009, 191:261-277.

32. Machado GB, de Assis MC, Leão R, Saliba AM, Silva MC, Suassuna JH, de Oliveira AV, Plotkowski MC: ExoU-induced vascular hyperpermeability and platelet activation in the course of experimental Pseudomonas aeruginosa pneumosepsis. Shock 2009, DOl: 10.1097/ SHK.0b013e3181b2b0f4.

doi:10.1186/1465-9921-11-4

Cite this article as: Cunha et al:: Potential mechanisms underlying the acute lung dysfunction and bacterial extrapulmonary dissemination during Burkholderia cenocepacia respiratory infection. Respiratory

Research 2010 11:4.

Publish with Biomed Central and every scientist can read your work free of charge

"BioMed Central will be the most significant development for disseminating the results of biomedical research in our lifetime. "

Sir Paul Nurse, Cancer Research UK

Your research papers will be:

- available free of charge to the entire biomedical community

- peer reviewed and published immediately upon acceptance

- cited in PubMed and archived on PubMed Central

- yours - you keep the copyright 